\title{
A relação Psicologia Comunitária e Behaviorismo: das críticas às propostas de diálogo
}

\section{The Relation Community Psychology and Behaviorism: From Critique to Dialogue}

\section{La Relación entre Psicología Comunitaria y Conductismo: de las Críticas hacia el Diálogo}

\author{
Thales Cavalcanti e Castro* \\ Universidade Federal de Goiás - UFG, Goiânia, Goiás, Brasil \\ Fernando Lacerda Júnior** \\ Universidade Federal de Goiás - UFG, Goiânia, Goiás, Brasil
}

\begin{abstract}
RESUMO
O presente trabalho analisa diferentes relações entre intervenção comunitária e Behaviorismo, problematizando a tese de que há um antagonismo entre ambos, e discute as possibilidades de um diálogo crítico entre Behaviorismo e Psicologia Comunitária. Para tanto, foi realizada uma análise bibliográfica, em que foram considerados três tipos de estudos: críticas dirigidas ao conservadorismo de teses behavioristas; reflexões behavioristas sobre intervenções comunitárias; relatos de trabalhos comunitários guiados por um referencial behaviorista. $\mathrm{Na}$ análise problematiza-se a relação Psicologia Comunitária e Behaviorismo destacando diferenças e aproximações entre os dois campos por meio de uma comparação entre as ideias de autores behavioristas e os pressupostos defendidos na Psicologia Comunitária. As principais divergências relacionamse com os temas sobre a participação comunitária e a relação colaborativa nas experiências comunitárias. Os pontos de convergência são identificados nos textos centrados em reflexões teóricas sobre colaboração, participação e o contexto da intervenção.
\end{abstract}

Palavras-chave: psicologia comunitária, behaviorismo, análise do comportamento.

\begin{abstract}
In this paper we analyze different relations between community intervention and Behaviorism questioning the thesis that there is an antagonistic relation between the latter and concerns with social transformation. Thus, this paper analyzes the possibilities for a dialogue between Behaviorism and Community Psychology. For this purpose, three types of papers were analyzed: criticisms of the conservatism of Behaviorism, reflections on community interventions from a behaviorist standpoint, reports of community interventions guided by Behaviorism. The relation Community Psychology-Behaviorism is discussed highlighting differences and similarities
\end{abstract}


between the two fields. The main differences are related to the issues of participation and collaboration in the analyzed interventions. As for convergences, the theoretical discussions regarding the need of collaboration and participation and a concern with interventions beyond the immediate context are highlighted.

Keywords: community psychology, behaviorism, behavior analysis, community intervention.

\begin{abstract}
RESUMEN
Este trabajo analiza diferencias entre la Psicología Comunitaria y el Conductismo con el fin de problematizar la tesis de que existe un antagonismo entre el último y las preocupaciones con la transformación social. Este análisis sirve a una reflexión sobre las posibilidades de diálogo entre el Conductismo y la Psicología Comunitaria. Se analizaron tres tipos de trabajos: críticas hacia el conservadurismo del Conductismo, teorías sobre intervenciones en comunidad desde el Conductismo; informes de intervenciones comunitarias guiadas por el Conductismo. Se analizan las relaciones Psicología Comunitaria-Conductismo destacando las diferencias y aproximaciones entre los dos campos. Las diferencias subrayadas son la falta de participación y colaboración en las intervenciones conductistas. Las convergencias son caracterizadas por discusiones teóricas sobre colaboración, participación y la preocupación con intervenciones más allá del contexto inmediato.
\end{abstract}

Palabras clave: psicología comunitaria, conductismo, análisis del comportamient.

\title{
1 Introdução
}

A busca por teorias e práticas que respondam a problemas sociais e problematizem o papel que o psicólogo deve ocupar na sociedade é necessária para o desenvolvimento de uma Psicologia comprometida com a transformação da realidade social. No seio da Psicologia, as produções acadêmicas e intervenções nem sempre se mostram comprometidas com essa transformação, mas algumas áreas apresentaram alguns pressupostos e intervenções que, explicitamente, buscaram a superação de processos opressivos.

Neste texto, são analisadas as possibilidades e as dificuldades para o diálogo entre um campo teórico, o Behaviorismo, e uma área específica, a Psicologia Comunitária. O primeiro, muitas vezes, é acusado de conservadorismo político, ainda que o tema da mudança seja frequente em seus textos. Já a Psicologia Comunitária ficou conhecida no Brasil por, explicitamente, se preocupar com o tema da mudança social. Por isso, o diálogo entre Behaviorismo e Psicologia Comunitária foi escolhido como tema deste trabalho.

Esta discussão não é original. Por exemplo, é possível encontrar propostas como a "Psicologia Comunitária Comportamental" (Behavioral Community Psychology) ou textos que discutiram a relação entre Psicologia Comunitária e Behaviorismo (Montero, 2004; Polanco, 2011). No entanto, são escassos os trabalhos que buscam 
estabelecer um diálogo entre as duas áreas. Assim, o presente trabalho apresenta possíveis relações entre a Psicologia Comunitária e ideias e experiências de trabalhos comunitários conduzidos a partir dos pressupostos e metodologias derivados do Behaviorismo analisando limitações e contribuições das propostas behavioristas para a análise, intervenção e avaliação dos problemas comunitários.

A relação entre Psicologia Comunitária e Behaviorismo é, neste trabalho, abordada discutindo três temas: as críticas realizadas por psicólogas e psicólogos comunitários ao Behaviorismo; trabalhos teóricos de behavioristas que apontam para uma necessidade de reformulação do que tem sido produzido na área; relatos de experiências comunitárias conduzidas a partir de referências behavioristas. Por fim, o trabalho problematiza a relação Behaviorismo-Psicologia Comunitária enfatizando aproximações entre produções teóricas realizadas na mesma época e destacando a possibilidade do diálogo entre as duas áreas.

\section{A Psicologia Comunitária e a crítica ao Behaviorismo}

A Psicologia Comunitária, como um novo campo de produção de conhecimentos e práticas, surge em um contexto de insatisfação com as teorias e práticas vigentes na Psicologia que, geralmente, psicologizavam problemas sociais. A partir daí, surgiram trabalhos que objetivam a superação de problemas psicossociais por meio da promoção de práticas que fortalecem a comunidade (Freitas, 2009; Góis, 2003; Lacerda Jr., 2010; Montero, 2004).

Vale ressaltar que há uma multiplicidade de teorizações e práticas sob o rótulo de "Psicologia Comunitária". Há trabalhos e autores que caminham em uma prática crítica, visando à transformação das comunidades, enquanto outros trabalhos são instrumentais para a manutenção do status quo (de la Torre, 1995; Freitas, 2005). A despeito da existência de divergências dentro do campo, alguns pontos comuns podem ser destacados. Por exemplo, há uma preocupação comum entre diferentes autores quanto à relevância social da psicologia e quanto à proposta de assumir as necessidades da comunidade como ponto de partida para o trabalho do psicólogo (Alfaro, 2000; Freitas, 1998; Montero, 2004).

Neste trabalho, é relevante enfatizar uma característica que pode ser identificada entre diferentes autores: a postura crítica em relação ao Behaviorismo. As críticas dirigidas às perspectivas comportamentais referem-se a aspectos como: visão individualista e perspectiva acrítica dos fenômenos estudados; isolamento do indivíduo do contexto histórico e social mais amplo; contrariedade aos ideais comunitários e transformadores (Montero, 1996; Prilleltenslky, 1994). Por exemplo, de acordo com Zonta (2010, p. 99): 
Para a perspectiva condutual ou comportamental fortemente influenciada por uma tradição positivista de ciência e comportamento, o foco central é o ambiente comunitário em seu sentido estrito, e a ação se volta para a resolução de problemas imediatos. Tendo como referência as condutas individualmente consideradas, os projetos são formatados de fora para dentro da comunidade, numa perspectiva de modificação do comportamento. Nesse enfoque, também não se consideram as determinações do modo de produção capitalista na construção subjetiva dos indivíduos.

Estas críticas resultaram em certa rejeição do referencial behaviorista na Psicologia Comunitária. No entanto, seria o Behaviorismo uma abordagem caracterizada apenas pelo conservadorismo político, pelo individualismo teórico e pelo a-historicismo? Ou existiria espaço para contradições, disputas e reconstruções teóricas no interior do Behaviorismo que resultaram em aproximação com ideais transformadores (Fawcett, 1991; Holland, 1978), diálogos com referenciais teóricos, como o marxismo, caracterizados pelo historicismo e pela crítica ao individualismo (Ulman, 1996)? Neste caso, não haveria possibilidades de um diálogo entre Behaviorismo e Psicologia Comunitária?

\section{Behaviorismo: espaço de manutenção do status quo e conservadorismo?}

O Behaviorismo, como campo de estudos e práticas, nasce na primeira metade do século XX. Behaviorismo1 é um termo "guardachuva" que, tal como o termo Psicologia Comunitária, abriga diversas vertentes com semelhanças, mas também importantes distinções teóricas. O que agrupa todas estas vertentes sob o mesmo termo é a ideia central de que uma ciência do comportamento é possível (Baum, 2006). Dentro do referencial analítico-comportamental, destaca-se a centralidade da interação do organismo com o ambiente externo para a determinação das condutas dos seres vivos.

As técnicas da Análise do Comportamento prometem melhorar a vida da sociedade à medida que se passe a usá-las com mais frequência. O fundador do Behaviorismo Radical, ao longo de suas obras, advogava que o uso dos princípios de uma ciência do comportamento humano pudesse servir para dirigir o comportamento dos indivíduos em direção a objetivos socialmente desejáveis (Skinner, 2003).

Essa visão, no entanto, é posta em questão por Prilleltensky (1991), segundo o qual o Behaviorismo seria uma representação da noção cultural prevalente de que a tecnologia possui as ferramentas 
necessárias para responder questões morais e éticas. Essa visão da ciência traz o risco de que os indivíduos sejam levados a acreditar que os conflitos sociais e morais são meras inconveniências técnicas e que o atual estado de coisas é justo, havendo apenas questões técnicas "entre a miséria e o alcance da felicidade" (p. 105).

Em outras palavras, a Psicologia, no afã de se converter em uma ciência, ignorou as dimensões éticas e morais em seu trabalho, o que leva, potencialmente, à manutenção do status quo. No Behaviorismo, por exemplo, houve o desenvolvimento de ferramentas terapêuticas eficazes, mas a falta de atenção aos valores foi um problema recorrente que abriu espaço para a utilização de procedimentos aversivos (como o uso de punições físicas, restrição de liberdades civis de encarcerados e pessoas dependentes de instituições), tentativas de alterar a orientação sexual de indivíduos, além de aplicações educacionais que enfatizaram a conformidade e docilidade de crianças (Nelson \& Prilleltensky, 2005).

Neste sentido, Dinsmoor (1992) aponta que, ainda que o reforçamento positivo seja preferível a técnicas aversivas, seria precipitado concluir que a mera substituição de um método pelo outro resolveria todos os problemas. Um método mais agradável não seria garantia de que não haveria produção de desigualdade e exploração de uma pessoa por outras.

Este tema é discutido por Holland (1978) que afirma que, mesmo quando um programa de modificação de comportamento parece inteiramente positivo, para os estratos superiores manterem a maior parte das riquezas e privilégios, restrição e coerção geralmente são necessárias para se manter o status quo. Holland (1978) afirma, por exemplo, que em um sistema de economia de fichas numa prisão, ainda são necessários guardas e muros para evitar que prisioneiros saiam antes do fim do programa. Da mesma forma, o uso da privação é requerido para algumas situações de reforçamento. Assim trabalhadores pobres trabalharão por ganhos limitados apenas se forem mantidos pobres.

A partir do exposto, pode-se notar que muitas das pesquisas e intervenções no campo da Análise do Comportamento não saem do ambiente imediato e não problematizam as estruturas sociais que geram os problemas. $\mathrm{Na}$ medida em que as intervenções ignoram as condições sociais e históricas nas quais os problemas são gerados e ocorrem, o ambiente imediato é tido como determinante dos fenômenos, o que contraria a expectativa e a capacidade de realização de análises mais amplas e torna a intervenção insustentável, já que a estrutura maior que produz os problemas continua inalterada.

Disso se conclui que as pesquisas e intervenções no campo do Behaviorismo reproduzem as hierarquias sociais e contribuem para a manutenção de relações de dominação. Mas será esse o único papel 
que cabe a ele?

\section{Behaviorismo, questão social e mudança social}

A despeito de não nascer voltado para as mesmas preocupações que a Psicologia Comunitária, há diversas produções pautadas no Behaviorismo que abordam a questão social e problemas comunitários. Neste sentido, encontra-se desde as discussões teóricas de Skinner na defesa dos princípios científicos para a solução de problemas sociais (Skinner, 2003; Malagodi, 1986), até relatos de trabalhos comunitários guiados pelo Behaviorismo (Abreu, 1990; Briscoe, Hoffman \& Bailey, 1975; Lombard, Neubauer, Canfield \& Winnett, 1991; Glenwick \& Jason, 1984).

Críticas ao Behaviorismo realizadas a partir da Psicologia Comunitária também foram tecidas por pesquisadores do próprio campo. A preocupação com intervenções que efetivamente promovam mudanças nos contextos de atuação levou psicólogos comportamentais à busca por novos valores para a pesquisa e a ação comunitária. Neste sentido, haveria outro papel para o analista do comportamento: mudar o sistema social que mantém o comportamento, criando novos ambientes ao invés de tentar modificar ambientes atuais (Nelson \& Prilleltensky, 2005).

A seguir são apresentados trabalhos que discutem a relação entre Behaviorismo e trabalhos comunitários (Fawcett, 1991; Glenwick \& Jason, 1984) e outro que busca, mais diretamente, uma articulação com o campo da Psicologia Comunitária (Bogat \& Jason, 2000).

O artigo de Glenwick e Jason (1984) é a introdução de um número especial do Journal of Community Psychology dedicado à "Psicologia Comunitária Comportamental" (PCC) que emergiu como uma vertente formalmente definida em meados dos anos 70. Os autores afirmam que a síntese da análise dos problemas sociais pela Psicologia Comunitária e dos princípios e metodologia da Psicologia Comportamental é o que define a PCC.

A PCC ressalta contribuições da Psicologia Comunitária ao criticar intervenções behavioristas que podem ser eficazes, mas rejeitadas com base na relação custo-benefício. Outra consideração sobre a intervenção é que esta nem sempre é congruente com os valores da comunidade. Assim, a PCC destaca a importância da avaliação da intervenção ser discutida com os grupos trabalhados, obtendo dados confiáveis e válidos, ao mesmo tempo em que se introduz a avaliação de modo integrado com a rotina da comunidade (Glenwick \& Jason, 1984).

Por outro lado, o Behaviorismo poderia dar uma contribuição à Psicologia Comunitária pela utilização de medidas objetivas e confiáveis e sua cuidadosa investigação de relações funcionais. 
Assim, a PCC é caracterizada pela proposição de projetos comunitários marcados pela formulação precisa de metas, especificação de componentes da intervenção e coleta de dados significativos dos resultados (Glenwick \& Jason, 1984).

Glenwick e Jason (1984) tratam também da validade social, isto é, do esforço para assegurar que os comportamentos alvo, procedimentos e resultados sejam relevantes e aceitáveis para ambientes nos quais as intervenções são conduzidas, implicando que haja avaliação por parte de pessoas da comunidade sobre a importância social do problema alvo, a aceitabilidade da técnica de intervenção e o significado dos resultados. Tais medidas podem auxiliar a localizar fontes e causas de questões que merecem atenção, assim como auxiliar o psicólogo comunitário comportamental na elaboração ou modificação de um projeto para aumentar a probabilidade de um resultado satisfatório para todos os envolvidos.

Ainda de acordo com Glenwick e Jason (1984), há uma série de desafios que a Psicologia Comunitária Comportamental deve enfrentar. Em primeiro lugar, boa parte das pesquisas no campo da PCC foi realizada com um pequeno número de sujeitos e nos níveis individuais e grupais, como os trabalhos de Cope e Allred (1991), com o objetivo de diminuir o uso ilegal de vagas de estacionamento reservadas a deficientes físicos e os trabalhos de Briscoe, Hoffman e Bailey, (1975) e Lombard et al. (1991), que serão analisados posteriormente. Por isso, o campo foi questionado quanto à sua habilidade de produzir mudanças significativas que pudessem alterar o status quo. Neste sentido, caberia à PCC elaborar intervenções mais amplas, nas quais pode ser necessário abrir mão de parte do controle experimental e ter flexibilidade na intervenção.

Em segundo lugar, os autores afirmam que os psicólogos comunitários comportamentais, com frequência, procuram maximizar suas contribuições e autoridade em um projeto. Tal estilo, ainda que bem sucedido em curto prazo, pode afetar negativamente a aceitação de um programa por uma comunidade em longo prazo e contrasta com aquele papel de natureza colaborativa, com o psicólogo trabalhando como consultor e parceiro dos grupos na comunidade, sugerido pela Psicologia Comunitária (Glenwick \& Jason, 1984). A adoção do estilo colaborativo envolve um abandono de controle e uma distribuição de poder, com um efeito reconhecidamente incerto sobre a eficácia do projeto. Se o modelo colaborativo, por um lado, traz uma ameaça à integridade do programa, no que diz respeito ao cuidado com os métodos e coleta de dados, seus benefícios potenciais para o desenvolvimento do campo se tornam cruciais para a produção de mudanças significativas e para colocar o controle das ações nas mãos de membros da comunidade (Glenwick \& Jason, 1984). 
Em outro trabalho, Fawcett (1991), no campo da Análise do Comportamento, avalia como, no campo da Análise do Comportamento, a pesquisa e a ação comunitária têm sido realizadas e apresenta um conjunto de valores e desafios com o objetivo de contribuir para o enfrentamento de problemas sociais. De acordo com o autor, a meta de mostrar efeitos notáveis e imediatos, geralmente com um pequeno número de pessoas, da pesquisa aplicada, tem desencorajado pesquisas de programas de prevenção que podem produzir efeitos relativamente não imediatos, mas que afetam toda a comunidade. Este padrão de pesquisa leva a evitar intervenções com variáveis ambientais mais amplas que afetam o comportamento no nível individual e comunitário.

Para contribuir para a compreensão das relações comportamentoambiente em espaços comunitários e facilitar o desenvolvimento de indivíduos e comunidades congruentes com suas próprias metas, Fawcett (1991) mostra um conjunto de desafios para a pesquisa e para a ação comunitária: evitar relações de "colonialismo" com os participantes, identificar os objetivos daqueles a quem a intervenção se dirige, selecionar participantes nas atividades de pesquisa e ação, planejar pequenas conquistas sobre os problemas comunitários e lidar com as diferentes audiências na pesquisa e na ação comunitária. A seleção e enquadre dos problemas são apontados como outro aspecto importante. Problemas comunitários são analisados pelo exame das interações entre o comportamento dos alvos principais e eventos ambientais físicos e sociais que definem contextos imediatos e mais amplos. Neste sentido, a escolha dos participantes deve ser consistente com a natureza multifatorial ou social dos problemas, com o modelo de mudança usado na intervenção e caracterizado por uma orientação direcionada às possibilidades da comunidade (Fawcett, 1991).

Ainda segundo Fawcett (1991), as condições rotuladas pelas pessoas como problemas estão geralmente relacionadas com 0 comportamento de múltiplos atores em vários níveis do sistema: membros das comunidades, prestadores de serviço e outros mediadores, funcionários eleitos e pessoas responsáveis por implementar leis e políticas que afetam a comunidade. Problemas de vários níveis exigem intervenções comunitárias em vários níveis. Neste sentido, diferentes modelos de mudança (prevenção, fortalecimento, difusão ou o desenvolvimento da comunidade) sugerem diferentes contextos e alvos para a intervenção. No entanto, o desafio de realizar mudanças em um nível comunitário mais amplo poderia contar com a estratégia de buscar pequenas conquistas, resultados concretos de importância modesta. Apesar de grandes efeitos em níveis mais amplos serem o objetivo final da intervenção, as pequenas conquistas poderiam ajudar o campo a manter as tentativas de integrar a pesquisa e ação comunitária. 
Por fim, Fawcett (1991) enfatiza que as intervenções comunitárias mais amplas demandam a adesão a um conjunto mais amplo de valores $^{2}$. O autor aponta quatro tipos de valores para a pesquisa e para a ação comunitária e suas implicações do ponto de vista da pesquisa e da comunidade: (a) valores para relações colaborativas - a pesquisa deve ser baseada no contexto local com a comunidade com relações colaborativas entre pesquisadores e participantes; (b) valores voltados para os objetivos da pesquisa e metodologia - os efeitos das intervenções de pesquisa devem ser replicáveis, duráveis e generalizáveis a outras pessoas e situações e as avaliações devem incluir o papel dos participantes na mudança de seus ambientes; (c) valores para intervenção e disseminação - as intervenções comunitárias devem buscar o uso de recursos e capacidades locais, enquanto os resultados devem ser apresentados e avaliados pela comunidade local, que deve receber informações de forma compreensível; (d) valores voltados para promoção e mudança comunitária - os projetos de pesquisa e ação comunitária devem contribuir para a compreensão de eventos ambientais que afetam o comportamento e, além disso, a pesquisa comunitária deve contribuir para o fortalecimento das pessoas em situação marginal.

Por fim, o trabalho de Bogat e Jason (2000) trata das razões pelas quais a Psicologia Comunitária Comportamental, apesar de dados teóricos e empíricos que demonstram sua utilidade e alcance, não se integrou com a Psicologia Comunitária, especialmente a vertente ecológica, e como uma colaboração mais significativa pode ser efetivada. Em primeiro lugar, os autores discutem diferenças filosóficas. Os dois campos enfatizam pontos de vista contrastantes da realidade: enquanto os behavioristas desenvolvem suas ideias a partir do ponto de vista do observador, independentemente do ponto de vista dos sujeitos, no modelo ecológico da Psicologia Comunitária a ênfase recai em uma relação colaborativa, ressaltando a importância da competência de cada pessoa, não apenas do profissional na definição e solução dos problemas.

De acordo com os autores, os psicólogos comunitários comportamentais - por acreditarem que certos eventos ambientais podem e devem ser mudados - sentem-se confortáveis promovendo mudanças controlando reforços e contingências. Este ponto de vista também se manifesta nas pesquisas comportamentais, nas quais raramente há descrição de como um comportamento ou ambiente foram definidos como um problema ou como uma intervenção foi elaborada. A ausência deste tipo de descrição pode não significar uma falta total de interesse em trabalhar como colaborador, mas indica uma tendência à formulação dos problemas e das soluções do ponto de vista do observador (Bogat \& Jason, 2000).

Bogat e Jason (2000) também discutem críticas dirigidas às teorias comportamentais. A maior delas seria a de que o Behaviorismo é 
capaz de descrever apenas o comportamento individual. Contudo, o fato da maior parte das intervenções comunitárias comportamentais ter sido conceituada no nível individual não prova que a teoria não é capaz de acomodar mudanças em níveis mais amplos. Os autores também destacam a crítica que afirma que as teorias comportamentais em contextos comunitários não produzem consequências duradouras. No entanto, Bogat e Jason (2000) argumentam que a efetividade da aplicação da teoria e da tecnologia comportamental pode ser ampliada pela atenção a reforçadores naturais e pela elaboração de uma tecnologia "contextualmente apropriada", isto é, efetiva, barata, descentralizada, flexível, sustentável e simples.

Os autores concluem sua discussão com a afirmação de que a prática da Psicologia Comunitária envolve grandes tarefas e que - Behaviorismo não oferece nenhuma solução mágica para estas dificuldades, mas suas ideias, se realmente integradas com a Psicologia Comunitária, podem fornecer novos caminhos para o trabalho com problemas sociais amplos usando pequenas conquistas ou, em termos comportamentais, aproximações sucessivas (Bogat \& Jason, 2000).

Os três trabalhos apresentados aqui sustentam a posição de que as teorias comportamentais podem ser utilizadas para realizações de mudanças comunitárias mais amplas. Os trabalhos afirmam que as intervenções devem se abrir à colaboração entre pesquisadores e participantes, permitindo a participação destes na escolha dos objetivos da pesquisa, o que ampliaria os benefícios para ambos. Ao lado da preocupação com a colaboração, destaca-se uma preocupação com a validade social, visando assegurar a aceitação e relevância dos comportamentos alvo, procedimentos e resultados para os participantes.

Apesar do destaque dado à colaboração em algumas discussões, aparentemente há poucos trabalhos que a incorporaram e há, até mesmo, outros que apresentam objeção à participação, já que esta poderia enviesar os dados (Fawcett, 1991). Contudo, nos trabalhos apresentados, os autores defendem que o processo de colaboração deve sempre ter lugar na intervenção, ampliando sua efetividade, seu alcance e, consequentemente, os benefícios para a comunidade.

Outra questão que merece atenção é a preocupação de que as intervenções sejam sustentáveis com o uso de recursos locais. Os trabalhos argumentam pela necessidade de existir uma preocupação com a viabilidade econômica da intervenção para que ela seja conduzida pela própria comunidade. Vale destacar que o uso de recursos locais também diz respeito aos recursos humanos, e a intervenções planejadas e conduzidas pelos moradores da comunidade. 
As discussões teóricas realizadas pelos autores analisados neste trabalho (Fawcett, 1991, Glenwick \& Jason, 1984, Bogat \& Jason, 2000) reconhecem que há problemas nas formas de condução das intervenções, mas apontam que com a implantação de algumas mudanças, como a utilização de recursos locais e a ampliação da colaboração da comunidade em todo o processo, tais intervenções podem produzir mudanças significativas no âmbito comunitário. Em síntese, são trabalhos que sustentam que há possibilidades de diálogo e convergência entre Behaviorismo e Psicologia Comunitária, contrariando, assim, a tese de que haveria uma contradição antagônica entre as duas áreas. No entanto, cabe analisar como este diálogo se dá na prática.

\section{Behaviorismo: relatos de intervenção}

As intervenções comunitárias realizadas a partir do Behaviorismo cobrem um amplo leque de problemas que afetam a comunidade. Alguns exemplos incluem: prevenção de acidentes de automóveis, diminuição do consumo de energia, prevenção de crimes, prevenção de doenças sexualmente transmissíveis, intervenções destinadas a aumentar o uso do cinto de segurança, prevenção de incêndios (Bogat \& Jason, 2000; Nietzel \& Himelein, 1987; Montesinos, Frisch, Greene, \& Hamilton, 1990; Johnson \& Geller, 1984; McConnell, Dwyer \& Leeming, 1996). Os métodos utilizados são variados, incluindo procedimentos de modelação, prompting, feedback, fading, reforçamento diferencial da resposta correta e delineamento de linha de base múltipla. Para compreensão do que tem sido produzido na área, três relatos de intervenção (Abreu, 1990; Briscoe, Hoffman \& Bailey, 1975; Lombard et al., 1991) são apresentados e analisados.

O trabalho de Abreu (1990) é um relato de uma experiência de utilização de métodos da Análise do Comportamento para controle e destinação adequada do lixo em uma comunidade de baixa renda. A favela onde a intervenção foi realizada tinha aproximadamente 6700 moradores. Apesar de haver caminhões que recolhiam lixos colocados em plataformas, a maioria dos moradores espalhava os resíduos nos quintais, ruas ou vielas. Dois estudos foram realizados com a finalidade de alterar comportamentos relacionados à coleta e triagem do lixo.

No primeiro, organizou-se uma equipe indicada por uma entidade comunitária que, com o assessoramento do autor, examinou as várias opções para encaminhar a solução do problema. Duas pessoas foram escolhidas para coletar o lixo das habitações. Os recursos para remunerar os coletores foram conseguidos de uma empresa coletora de lixo na região que se comprometeu com a doação de dois saláriosmínimos. Com o início dos procedimentos, a média semanal de lixo 
depositado passou de $884 \mathrm{~kg}$ para $2291 \mathrm{~kg}$. O segundo estudo - de triagem domiciliar dos resíduos sólidos - foi motivado pela dificuldade em triar os itens comercializáveis, o que tomava tempo e estava comprometendo a coleta. A comissão de moradores resolveu tentar fazer algo para que os próprios moradores triassem seus rejeitos. O estudo compreendeu uma única fase com delineamento de linha de base múltipla ${ }^{3}$, com a favela dividida em três áreas com inícios diferentes quanto à exigência de triagem do lixo. Na rua $A$, a triagem chegou a $63 \%$ das habitações e estabilizou-se em cerca de $50 \%$. Na rua $B$, chegou a $83 \%$ e estabilizou-se em cerca de $50 \%$. Na rua C o maior percentual conseguido foi $38 \%$.

Abreu (1990) salienta que foi possível realizar uma intervenção na qual os objetivos e os meios para alcançá-los estavam sob o controle da população. Afirma também que "uma vez adequadamente dispostas certas condições, as coletividades podem tornar-se mais autônomas e independentes para tomar decisões que as beneficiem" (p. 405). O autor, por fim, destaca que o trabalho poderia ter sido mais abrangente se tivesse contado com outros profissionais e afirma que, mesmo um trabalho interdisciplinar, não dispensa 0 estabelecimento de uma política governamental dirigida às condições de vida, especialmente das populações de baixa renda.

O segundo trabalho, de Briscoe, Hoffman e Bailey (1975), traz o relato de uma intervenção com membros de um conselho comunitário de um projeto financiado pelo governo federal dos Estados Unidos cujo objetivo era o desenvolvimento de um programa de ensino de habilidades específicas de resolução de problemas. Além disso, buscava facilitar a participação ativa dos representantes da comunidade na resolução de problemas e na tomada de decisões.

Com seis participantes, eleitos por moradores locais durante reuniões comunitárias, a maior parte das decisões do conselho era tomada durante reuniões semanais com ênfase na identificação e resolução de problemas locais, tais como: reparos no centro comunitário, organização de eventos sociais e educacionais, achar e oferecer auxílio médico e administrar a verba destinada a esses projetos.

A fim de garantir a frequência dos participantes no projeto, cada um recebeu uma pequena quantia em dinheiro para cada reunião frequentada durante o período de estudo, que compreendeu 0 acompanhamento de dezoito reuniões.

A análise da observação das reuniões sugeriu aos pesquisadores três passos para uma efetiva resolução de problemas: (1) identificação e isolamento do problema em discussão, (2) declaração e avaliação de soluções alternativas e (3) seleção de uma solução e tomada de decisões explícitas para sua implementação (o que deveria ser feito, por quem, quando e como). Deste modo, para o estudo em questão, os comportamentos de resolução de problemas foram definidos e divididos em três grandes categorias: (1) identificação do problema 
(declarações como "o problema é..." ou frases equivalentes); (2) resolução do problema (declarações como "uma solução é...", "outra solução seria..."); (3) decisões sobre as ações a serem tomadas (frases como "quem será o responsável?" ou "quando a ação será realizada?" dirigidas a outro membro).

A intervenção foi realizada com um delineamento de linha de base múltipla e os resultados indicaram que todos os comportamentos aumentaram no treino em função da intervenção. $\mathrm{Na}$ fase de acompanhamento (follow-up) foi observado um gradual declínio nas afirmações relacionadas aos problemas nos seis encontros que se seguiram ao treinamento. O número de afirmações relacionadas à solução também se reduziu, mas voltou a aumentar. Afirmações relacionadas às ações a serem efetivadas permaneceram altas.

O trabalho é concluído com a afirmação de que uma abordagem comportamental para a Psicologia Comunitária pode representar um ponto de partida útil com soluções novas e de sucesso para problemas comunitários de longo prazo.

O terceiro trabalho, de Lombard et al. (1991), teve por objetivo a promoção de comportamentos de proteção (como uso de protetor solar, uso de roupas adequadas e redução da exposição ao sol) para prevenção do câncer de pele. A pesquisa foi conduzida em dois clubes. Durante a intervenção foram dispostos cartazes em frente à piscina com informações sobre como se proteger do sol, panfletos informativos foram disponibilizados com informações sobre causas e perigos do câncer de pele e estratégias de prevenção; houve feedback de proteção dos riscos e metas através de cartazes com a porcentagem de crianças e adultos que apresentaram dois ou mais comportamentos de proteção no dia anterior. A intervenção contou ainda com uma sessão de treinamento durante a qual os salva vidas eram informados sobre os comportamentos alvo e ensinados a iniciar conversas apoiando esses comportamentos e foi feita a divulgação de uma "rifa do compromisso", através de panfletos distribuídos com a afirmação de que se as crianças preenchessem um cartão de compromisso prometendo praticar os comportamentos alvo, ganhariam chapéus e camisetas relacionados aos comportamentos seguros quando a meta de $40 \%$ de comportamentos de proteção por três dias consecutivos fosse alcançada. Nenhum dos clubes atingiu 0 critério de $40 \%$ por três dias consecutivos. Entre os comportamentos alvo para os frequentadores, os maiores aumentos foram observados na permanência na sombra para todas as idades e uso de camisetas para crianças. No final de seu trabalho, Lombard et al. (1991) ressaltam que o aumento dos comportamentos de proteção foi modesto e decréscimos foram observados no final da intervenção em ambos os clubes.

Os trabalhos relatados compreenderam diferentes níveis de intervenção. No trabalho de Lombard et al. (1991), o foco da 
intervenção foi o comportamento de indivíduos que frequentavam um espaço de lazer. No trabalho de Briscoe, Hoffman e Bailey (1975) e de Abreu (1990), o objetivo da intervenção é, direta ou indiretamente, promover mudanças na comunidade e trabalhar com representantes comunitários. Ambos os trabalhos apresentam a semelhança de intervirem em grupos responsáveis pela tomada de decisões que afetam a comunidade, não sendo os pesquisadores responsáveis diretos por mudanças na comunidade.

$\mathrm{Na}$ intervenção de Abreu (1990) merece destaque o fato de que a intervenção e contato com a comunidade não se restringiram ao grupo responsável pela tomada de decisões e condução do processo, mas se estenderam a outros moradores da comunidade. Nesta intervenção, a comunidade assumiu um papel ativo na condução do trabalho. Assim, foi, também, uma intervenção com a comunidade.

No trabalho de Briscoe, Hoffman e Bailey (1975) com os membros do conselho comunitário, os participantes foram reconhecidos como responsáveis por decisões, mas não houve participação da população alvo na definição da intervenção, estando os pesquisadores em uma posição privilegiada. No trabalho de Lombard e cols. (1991), isto é ainda mais destacado. Nesta pesquisa, não houve envolvimento dos pesquisadores com os sujeitos da pesquisa e ocorreu até mesmo uma ameaça de demissão com aprovação implícita dos pesquisadores.

A partir da leitura dos trabalhos que relatam experiências comunitárias do Behaviorismo, pode-se perceber que, de modo geral, há um descompasso entre os caminhos apontados nos trabalhos teóricos e a condução das intervenções. Um exemplo disso é que, enquanto nos trabalhos de discussão de princípios e ideias destaca-se a colaboração dos sujeitos envolvidos na pesquisa e ação, incluindo a definição dos objetivos, em nenhum dos trabalhos de intervenção analisados os problemas foram definidos pela própria comunidade.

Nos relatos de Lombard et al. (1991) e de Briscoe, Hoffman e Bailey (1975), os comportamentos alvo e os métodos de intervenção foram definidos pelos próprios pesquisadores. No estudo de Lombard et al. (1991), a intervenção não obteve o resultado esperado e, mesmo assim, não se discutiu a ampliação da participação dos sujeitos envolvidos. Cabe ressaltar, novamente, a distância entre a população em estudo e os pesquisadores, havendo uma ameaça de demissão aos salva-vidas, em função da intervenção, sem que os pesquisadores se pronunciassem a respeito. No trabalho de Briscoe, Hoffman e Bailey (1975), os passos da intervenção foram definidos a partir do problema, mas não com os participantes. Pode-se dizer que a intervenção foi feita para a comunidade, mas não com ela. Os métodos de intervenção são detalhados, mas ficaram sob o controle dos pesquisadores.

A intervenção de Abreu (1990) diverge parcialmente dos outros trabalhos neste sentido. Apesar de não contar com a participação da 
comunidade na definição do problema, o trabalho tinha como objetivo que os próprios moradores tivessem competência para intervir no problema, cabendo ao psicólogo o papel de consultor. O controle da intervenção esteve nas mãos da comunidade, mais especificamente do grupo da União de Moradores. Contudo, o autor não menciona como o contato com a comunidade foi estabelecido.

A sustentabilidade das intervenções com recursos locais é outro ponto que deve ser discutido, pois também é um tema que aparece nos textos teóricos analisados (Fawcett, 1991; Bogat \& Jason, 2000), mas não nos relatos de experiência. No trabalho de Lombard et al. (1991), a rifa utilizada é um dos exemplos de uso de recursos externos em detrimento de recursos do próprio ambiente. Os recursos são dos próprios pesquisadores, o que poderia não garantir a continuidade da intervenção caso os pesquisadores se retirassem daquele ambiente.

No trabalho de Briscoe, Hoffman e Bailey (1975), o pagamento pela frequência nas reuniões mostra que não estavam sendo usados recursos da própria comunidade. O treinamento foi realizado de forma individual, sem utilizar recursos da própria comunidade, mas o conhecimento dos próprios pesquisadores. Apenas no trabalho de Abreu (1990), o uso de recursos locais é evidente. A medida do lixo foi feita pelo autor e por crianças da comunidade. A coleta do lixo foi realizada por dois moradores da própria comunidade com recursos que, apesar de serem externos, de uma empresa coletora de lixo da região, foram conseguidos pelos moradores e não um recurso que depende da presença do pesquisador.

Do ponto de vista analítico-comportamental, a sustentabilidade pode ser entendida como 0 estabelecimento de contingências naturais, mais eficazes no controle e manutenção dos repertórios construídos. Nestas contingências, o comportamento é mantido por seus próprios produtos naturais, não dependendo da presença de agentes externos. Glenwick e Jason (1984) afirmam que a Psicologia Comunitária Comportamental poderia se beneficiar de uma maior ênfase na identificação, validação e criação de ambientes de apoio cujas contingências naturais sustentariam o desenvolvimento do companheirismo, autonomia e autossuficiência.

Um ponto que vale a pena ser ressaltado é que o acompanhamento da intervenção no trabalho de Abreu (1990) se estendeu por mais de um semestre e mostra os efeitos da intervenção na comunidade. No trabalho de Briscoe, Hoffman e Bailey (1975), o acompanhamento foi por um tempo reduzido (cerca de seis reuniões). Um problema, reconhecido pelos próprios autores, é a falta de informação quanto ao sucesso dos objetivos do conselho, não avaliando os impactos da própria intervenção. Na intervenção de Lombard et al. (1990) não houve acompanhamento após a intervenção. 
Como já exposto anteriormente, alguns textos sobre princípios e discussões problematizam a questão do status quo no Behaviorismo (Glenwick e Jason, 1984; Fawcet, 1991; Bogat e Jason, 2000). Nota-se que esta preocupação não está tão presente nos relatos de intervenção. As discussões realizadas no campo teórico remetem à necessidade de intervenções em níveis mais amplos, mas as práticas analisadas neste trabalho não acompanham o discurso. Porém, apesar das limitações no que foi, efetivamente, conduzido na prática, os trabalhos apontam interfaces e possibilidades de contribuição para a área da Psicologia Comunitária. Na próxima seção, serão discutidas algumas delas.

\section{Possíveis diálogos entre a Psicologia Comunitária e o Behaviorismo}

Contextos de pesquisa e intervenção diferentes exigem novas maneiras de se estudar e intervir. Esta ideia aproxima o Behaviorismo das discussões da Psicologia Comunitária sobre a inserção do psicólogo em novos espaços e a insatisfação com as teorias vigentes na Psicologia com sua natureza associal e foco no indivíduo. Nesse sentido, a aproximação com a questão social aponta para novos caminhos que o Behaviorismo deveria seguir para ter sucesso nas intervenções no âmbito comunitário.

Quase ao mesmo tempo em que se desenvolviam as primeiras reflexões sobre o papel da Psicologia na comunidade, Glenwick e Jason (1984) publicaram um texto tematizando questões centrais para a atuação do behaviorista na comunidade. Neste texto, assim como em outros apresentados anteriormente, é possível identificar muitas convergências com questões levantadas na Psicologia Comunitária latino-americana. Algumas delas são destacadas a seguir.

De acordo com o Fawcett (1991) e Glenwick e Jason (1984), a produção de mudanças mais amplas e significativas implica em abrir mão de parte do controle experimental. No âmbito da Psicologia Comunitária, esta também é uma preocupação presente, por exemplo, quando Freitas (1998) afirma que as diretrizes e características das estratégias e instrumentais empregados na análise de necessidades afastam-se de métodos tradicionais de pesquisa marcados por maior controle sobre a situação e o contexto de coleta de dados. Já Montero (2004) destaca a pesquisa-ação participativa, método em que a pesquisa e a intervenção também estão sob o controle da comunidade.

Uma segunda mudança proposta por Jason e Glenwick (1984), destaca a necessidade de se estabelecer relações de colaboração com a população com a qual se busca desenvolver a intervenção, 
obtendo opiniões sobre como enquadrar a questão que é objeto da intervenção e quais são os objetivos valorizados pela comunidade. Dessa forma, a meta final é desenvolver uma organização que promova as habilidades necessárias para que a população se organize sem ajuda de agentes externos. Esta preocupação com a colaboração (ver também, Fawcett, 1991) aproxima as intervenções comportamentais no âmbito comunitário da Psicologia Comunitária. Ela converge com a preocupação de Freitas (1998) sobre como a inserção deve se dar com a participação da comunidade na busca pela construção de alternativas de ação frente aos problemas que assolam a comunidade.

Outro ponto de destaque de convergências relaciona-se com as pequenas conquistas. Para Bogat e Jason (2000), elas não são o objetivo final da intervenção comunitária, mas, por outro lado, também não são incompatíveis com mudanças mais amplas e podem chamar a atenção do público (e da pesquisa comunitária) para o problema maior a ser transformado. Em termos comportamentais pode-se dizer que as pequenas conquistas podem reforçar 0 comportamento de engajamento dos pesquisadores e dos membros da comunidade envolvidos na intervenção.

Assim, o objetivo final do psicólogo comportamental que atua no âmbito comunitário seria o de auxiliar no desenvolvimento de competências para que a comunidade possa lidar com os próprios problemas e, como apontam Glenwick e Jason (1984), continuar com a intervenção da mesma forma. Esta discussão se aproxima daquela realizada por Montero (2004), para quem o agente externo serviria como catalisador de uma ação transformadora. A transformação da comunidade não tem como norte da intervenção a dependência em relação a um agente externo, mas a autonomia da própria comunidade, isto é, que ela seja capaz de construir alternativas de ação.

Da mesma forma, a discussão sobre as pequenas conquistas proposta por Fawcett (1991) converge com discussões realizadas por psicólogos comunitários sobre como intervenções locais podem ser ligadas a mudanças mais amplas. De acordo com Nelson e Prilleltensky (2005), por um lado, intervenções individuais e em pequenos grupos trazem o risco de passar uma mensagem de que o que deve mudar está na esfera psicológica, mas, por outro lado, essas intervenções, podem estar articuladas com preocupações com a transformação das esferas socioeconômicas mais amplas. Neste caso, podem ser consideradas ações características da Psicologia Comunitária que busca transformação social.

Um último ponto de destaque do Behaviorismo que o aproxima da Psicologia Comunitária, é que ele vai além de uma posição que culpabiliza as vítimas. Segundo Malagodi (1986): "os problemas sociais se originam em ambientes sociais, não nas mentes de 
indivíduos, e soluções para eles só podem ser alcançadas pela mudança radical de contingências ambientais" (p. 4). Este destaque se aproxima do psicólogo comunitário Ryan (1971 como citado em Krause Jacob, 2007) para o qual:

quando os problemas eram definidos em termos econômicos, sociais ou culturais, ou seja, quando suas causas eram atribuídas às condições contextuais da pessoa individual, as soluções coerentes eram de outro tipo, tendendo às intervenções comunitárias, sociais ou políticas e, com isso, à mudança social (p. 77-78).

O foco nas contingências ambientais vai de encontro a uma posição que formula os problemas comunitários como características patológicas dos indivíduos, mas coloca em pauta a necessidade de realizar intervenções nas condições que mantêm os problemas sociais.

Além das convergências, pontos de divergências foram observados nos trabalhos analisados. Um deles diz respeito à defesa da replicabilidade das intervenções como um valor de pesquisa apontado por Fawcett (1991). A avaliação dos resultados é importante para avaliar a efetividade da intervenção e, de fato, pode existir a reutilização de alguns instrumentos de avaliação. Contudo, a replicação dos procedimentos não leva em consideração a diferença de recursos e participação em cada comunidade. Alfaro (2000), Freitas (1998) e Montero (2004) argumentam que é a relevância social e as necessidades que devem ditar o trabalho comunitário e não as problemáticas que caracterizaram a história da Psicologia hegemônica. Esses autores convergem na admissão de possibilidades de mudanças quanto às estratégias, objetivos e problemáticas a serem trabalhadas pelo profissional ou pesquisador. A Psicologia Comunitária deve estar focada nas necessidades específicas dos grupos com que trabalha.

Outro ponto de divergência, que aparece nos trabalhos de Briscoe, Hoffman e Bailey (1975) e de Lombard et al. (1991), é o uso de recursos externos à comunidade na intervenção e a definição da intervenção sem participação comunitária, o que poderia não garantir a continuidade da intervenção caso os pesquisadores se retirassem daquele ambiente. Podemos identificar uma diferença significativa com a perspectiva defendida por Montero (2004), quem argumenta que a Psicologia Comunitária deve trabalhar na, com e para a comunidade. A falta de participação e do controle ativo no processo de trabalho coloca a comunidade numa posição dependente que fomenta a passividade. Montero (2004) afirma que isso não significa que os agentes externos não podem ter iniciativa, mas que é necessário existir participação comunitária para que ocorra 
um encontro de decisões e reflexões entre agentes externos e as comunidades, as quais devem ter acesso ao controle sobre o que se faz. Este procedimento possibilita o fortalecimento comunitário. Neste sentido, Freitas (1998) defende uma forma de inserção na comunidade, na qual tanto os profissionais quanto a comunidade estabelecem relações horizontais de discussão, análise e definição de problemas, sem identidades e papéis fixos. Os objetivos são definidos a posteriori, em um processo decisório participativo, que permite levantar alternativas de ação junto à população para que esta possa assumir sua própria história.

Finalmente, cabe ressaltar que, apesar das preocupações com intervenções que buscam "mudança social", não foi possível identificar com clareza o que significa "mudança" nos textos analisados. Os relatos de intervenção (Abreu, 1990; Briscoe, Hoffman \& Bailey, 1975; Lombard et al., 1991) apontam para melhorias na qualidade de vida da população alvo, enquanto as discussões teóricas (Bogat \& Jason, 2000; Fawcett, 1991; Glenwick \& Jason, 1984) parecem tratar da "mudança social" como "reforma social". São feitas críticas ao controle social estratificado, mas sem pautar transformações radicais. Essa orientação contrasta com aquela adotada pela psicologia social comunitária latino-americana, a qual, segundo Sawaia, "é concebida como transformação de uma sociedade exploradora e, portanto, como revolução socialista ou cidadã" (1996, p. 46-47). Essas observações parecem estar de acordo com Ulman (1996) que, apesar de afirmar que alguns analistas do comportamento terem se tornado politicamente radicais, reconhece que são "poucos se aventuram além dos limites do programa de reforma gradual, fragmentada" (p. 84).

\section{Considerações finais}

O presente trabalho teve como objetivo avaliar possíveis diálogos entre Behaviorismo e Psicologia Comunitária. A discussão identificou pontos de divergência e convergência e que os textos behavioristas tendem a ser mais convergentes com a Psicologia Comunitária quando estão analisando princípios e teorias e mais divergentes quando estão relatando experiências.

As principais divergências entre Behaviorismo e Psicologia Comunitária dizem respeito à falta de participação dos sujeitos presentes nas experiências relatadas. Seguindo um caminho oposto às propostas da Psicologia Comunitária, as experiências não incluíram os sujeitos na definição dos problemas dos projetos de intervenção e também não estabeleceram parcerias colaborativas. No entanto, nas discussões teóricas do próprio campo behaviorista sobre trabalhos 
comunitários há forte ênfase sobre a necessidade de participação e colaboração. Além disso, a preocupação com intervenções que não se restrinjam ao contexto imediato e a ênfase na necessidade de mudanças mais amplas é outro ponto de convergência entre Psicologia Comunitária e certas elaborações teóricas do Behaviorismo. A partir dessa discussão, é possível afirmar que não há uma antítese essencial entre Behaviorismo e Psicologia Comunitária e que as primeiras elaborações da Psicologia Comunitária surgiram no mesmo período histórico em que behavioristas apresentavam críticas ao próprio campo e afirmavam a necessidade de elaborar intervenções comunitárias, colaborativas e transformadoras.

Identificou-se, também, que as interfaces entre Behaviorismo e questões sociais e comunitárias, podem ser divididas em dois grupos. O primeiro, como exemplificado por alguns trabalhos de intervenção, trabalha com a mudança de alguns aspectos pontuais do ambiente visando alterar o comportamento dos indivíduos em relação a alguma questão em particular. No segundo grupo estão os trabalhos que consideram que uma efetiva aplicação dos princípios behavioristas demanda uma mudança de aspectos estruturais da sociedade. Nesta segunda posição, reconhece-se que o tratamento da questão social e de problemas comunitários na perspectiva da Análise do Comportamento, e do Behaviorismo em geral, ainda é incipiente, mas pode contribuir para transformações sociais mais amplas.

Assim como a Psicologia Comunitária não se constitui como um campo homogêneo, os psicólogos comportamentais não estão comprometidos com um único projeto social. No campo do Behaviorismo, há desde aqueles que visam melhorar a sociedade atual, com o objetivo de melhorar a qualidade de vida daqueles a quem se dirige a intervenção, até aqueles que visam transformá-la radicalmente. Este cenário não é diferente da Psicologia Comunitária, na qual, tal como afirma Montero (2004) convivem diversos projetos e metodologias. Apesar de os textos discutidos não avançarem quanto à profundidade das mudanças sociais, há trabalhos como os de Holland $(1973 ; 1978)$ que apontam claramente para a necessidade de contribuições do Behaviorismo para processos de transformação social. Neste sentido, tanto o Behaviorismo quanto a Psicologia Comunitária podem estar a serviço da reprodução do status quo ou na busca pela produção de mudanças significativas que possam alterá-lo.

Se, de um lado, existem dúvidas quanto à capacidade das intervenções comportamentais de promover mudanças significativas, de outro, pode-se dizer que nem o Behaviorismo, nem a Psicologia Comunitária, nem a Psicologia em geral, são capazes de promover mudanças mais amplas, que conduzem à transformação social (Yamamoto, 1987). Há que se reconhecer que o impacto das intervenções é limitado e uma transformação social ampla dependeria 
da participação das massas, em grande escala.

Uma interface entre as duas áreas pode contribuir para um redirecionamento do Behaviorismo em direção a um novo compromisso social e fortalecer a Psicologia Comunitária com instrumentais de avaliação e intervenção que permitam o desenvolvimento comunitário.

\section{Referências}

Abreu, J. L. C. (1990). Controle dos resíduos sólidos com envolvimento de população de baixa renda. Revista de Saúde Pública, 24(5), 398-40.

Alfaro, J. (2000). Discusiones en Psicología Comunitaria. Santiago: Universidad Diego Portales.

Baum, W. M. (2006). Compreender o behaviorismo: comportamento, cultura e evolução ( $2^{\mathrm{a}}$ ed.). Porto Alegre: ARTMED.

Bogat, A. G., \& Jason, L. A. (2000). Toward an integration of behaviorism and community psychology: Dogs bark at those they do not recognize. In: J. Rappaport \& E. Seidman (Orgs.), Handbook of community psychology, (pp. 101-114). New York: Kluwer Academic/Plenum.

Briscoe, R. V., Hoffman, D. B., \& Bailey, J. S. (1975). Behavioral community psychology: Training a community board to problem solve. Journal of Applied Behavior Analysis, 8(2), 157-168.

Cope, J. G., \& Allred, L. J. (1991) Community Intervention to Deter Illegal Parking in Spaces Reserved for the Physically Disabled. Journal of Applied Behavior Analysis, 24(4), 687-693.

De la Torre, C. (1995). Psicología Latinoamericana: entre la dependencia y la identidad. Havana: Editorial Felix Varela; reprinted, 2010, Buenos Aires: Paidós.

Dinsmoor, J. A. (1992). Setting the record straight: The social views of B. F. Skinner. American Psychologist, 47(11), 1454-1463.

Fawcett, S. B. (1991) Some Values Guiding Community Research and Action. Journal of Applied Behavior Analysis, 24(4), 621-636.

Freitas, M. F. Q. (1998). Inserção na comunidade e análise de necessidades: reflexões sobre a prática do psicólogo. Psicologia: Reflexão e Crítica, 11(1), 185-189.

Freitas, M. F. Q. (2005) (In)Coerências entre práticas psicossocias em comunidade e projetos de transformação social: aproximações entre as Psicologias Sociais da Libertação e Comunitária. PSICO, 36(1), 47-54.

Freitas, M. F. Q. (2009). Psicologia na Comunidade, Psicologia da Comunidade e Psicologia (Social) Comunitária - Práticas da Psicologia em Comunidade nas Décadas de 60 a 90, no Brasil. In: R. H. F. Campos (Org.). Psicologia Social Comunitária: da 
Solidariedade à Autonomia (pp. 54-80). Petrópolis - RJ: Vozes.

Glenwick, D. S., \& Jason, L. A. (1984). Behavioral community psychology: An introduction to the special issue. Journal of Community Psychology, 12, 103-112.

Góis, C. W. L. (2003). Psicologia Comunitária no Ceará: Uma caminhada. Fortaleza: Instituto Paulo Freire de Estudos Psicossociais.

Holland, J. G. (1973) ¿Servirán los principios conductuales para los revolucionarios? In: F. S. Keller \& E. R. Iñesta (Eds.), Modificación de Conduta: Aplicaciones a la educación (pp. 265281). México: Trillas.

Holland, J. G. (1978). Behaviorism: Part of the problem or part of the solution. Journal of Applied. Behavior Analysis, 11(1), 163-174.

Johnson, R. P., \& Geller, E. S. (1984). Contingent versus noncontingent rewards for promoting seat belt usage. Journal of Community Psychology, 12(2), 113- 122

Krause Jacob, M. (2007). Discusión crítica de la práctica de intervención psicológico-comunitaria en Santiago de Chile. In: J. A. Inzunza \& H. B. Torres (Orgs.). Trayectoria de la Psicología Comunitaria en Chile: Prácticas y conceptos (pp. 245-258). Valparaíso: Universidad de Valparaíso Editorial.

Lacerda Jr, F. (2010). Notas sobre o desenvolvimento da psicologia social comunitária. In: R. Guzzo \&. F. Lacerda Jr. (Orgs.). Psicologia e Sociedade: Interfaces no debate da questão social (1a Ed., pp. 19-41). Campinas: Alínea.

Lombard, D., Neubauer, T. E., Canfield, D., \& Winnett, R. A. (1991). Behavioral community intervention to reduce the risk of skin cancer. Journal of Applied Behavior Analysis, 24(4), 621-636.

Malagodi, E. F. (1986). On radicalizing behaviorism: A call for cultural analysis. The Behavior Analyst, 9(1), 1-17.

McConnell, A. F., Dwyer, W. O., \& Leeming, F. C. (1996). A behavioral approach to reducing fires in public housing. Journal of Community Psychology, 24(3), 201-212.

Montero, M. (1996). Paradigmas, corrientes y tendencias de la psicología social finisecular. Psicologia \& Sociedade, 8(1), 102119.

Montero, M. (2004). Introducción a la psicología comunitaria: Desarrollos, conceptos y procesos. Buenos Aires: Paidós.

Montesinos, L., Frisch, L. E., Greene, B. F., \& Hamilton, M. (1990). An analysis of and intervention in the sexual transmission of disease. Journal of Applied Behavior Analysis, 23(3), 275-284.

Nelson, N., \& Prilleltensky, I. (2005). Community Psychology: In pursuit of liberation and well-being. New York: Palgrave McMillan.

Nietzel, M. T., \& Himelein, M. J. (1987). Crime prevention through social and physical environmental change. The Behavior 
Analyst, $10(1), 69-74$

Polanco, F. A. (2011). Psicología Comunitaria en el Río de la Plata: Algunos aportes conceptuales y prácticos desde el conductismo. Revista DiáLogos, 2(2), 83-91.

Prilleltensky, I. (1991). Radical behaviorism and the social order. Counseling \& Values, 36(2), 104-111.

Prilleltensky, I. (1994). The morals and politics of psychology: Psychological discourse and the status quo. Albany: State University of New York Press.

Rivière, V. (2006). Analyse Analyse du comportement appliquée à l'enfant et à l'adolescent. Villeneuve d'Ascq: Presses Universitaires du Septentrion.

Sawaia, B. B. (1996). Comunidade: A apropriação científica de um conceito tão antigo quanto a humanidade. In: R. H. F. Campos (Org.) Psicologia Social Comunitária - da solidariedade à autonomia. (6 $6^{\mathrm{a}}$ ed.). Rio de Janeiro: Vozes.

Skinner, B. F (2003). Ciência e Comportamento Humano (11a Ed.). São Paulo: Martins Fontes.

Ulman, J. D. (1996). Radical behaviourism, selectionism, and social action. In: I. Parker \& R. Spears (Eds.), Psychology and society: Radical theory and practice (pp. 81-92). Londres: Pluto.

Velasco, S. M., Garcia-Mijares, M., \& Tomanari, G.Y. (2010). Fundamentos Metodológicos da Pesquisa em Análise Experimental do Comportamento. Psicologia em pesquisa, 4(2), 150-155.

Yamamoto, O. H. (1987). A crise e as alternativas da psicologia. São Paulo: Edicon.

Zonta, C. (2010). Aspectos educativos envolvidos no processo de apropriação do conhecimento e desenvolvimento da consciência nas práticas comunitárias. In R. Guzzo e F. Lacerda Jr. (Orgs.), Psicologia e Sociedade: Interfaces no debate da questão social (1a ed., pp. 99-117). Campinas: Alínea Editora.

\section{Endereço para correspondência}

Thales Cavalcanti e Castro

Universidade Federal de Goiás

Centro de Ensino e Pesquisa Aplicada à Educação (CEPAE)

Campus Samambaia, Setor Itatiaia, Caixa-postal 131, CEP 74001970, Goiânia GO, Brasil

Endereço eletrônico: thales@ufg.br

Fernando Lacerda Júnior

Universidade Federal de Goiás

Faculdade de Educação

Rua 235, s/n, Setor Leste Universitário, CEP 74605-050 Goiânia, GO - Brasil

Endereço eletrônico: fernando_lac@yahoo.com.br

Recebido em: 28/03/2014

Reformulado em: 01/09/2014 
Aceito para publicação em: 02/09/2014

\section{Notas}

* Graduação em Psicologia pela Universidade Federal de Goiás. Mestrando do Programa de Pós-Graduação em Psicologia da Universidade Federal de Goiás. Psicólogo do Centro de Ensino e Pesquisa Aplicada à Educação da Universidade Federal de Goiás, Goiânia, Goiás, Brasil.

** Graduação e Doutorado em Psicologia pela Pontifícia Universidade Católica de Campinas. Professor Adjunto de Psicologia Social da Faculdade de Educação da Universidade Federal de Goiás (UFG), Goiânia, Goiás, Brasil.

1 No presente trabalho optou-se por trabalhar com um termo mais amplo ("Behaviorismo") em função de algumas características da literatura pesquisada: estudos citados neste trabalho usam o termo "Behaviorismo" sem especificar uma vertente, ainda que a análise dos trabalhos permite traçar uma aproximação com os pressupostos do Behaviorismo Radical e da Análise do Comportamento. Por exemplo, Glenwick e Jason (1984) em uma classificação de intervenções comunitárias comportamentais reconhecem a existência de várias vertentes: "Procedimentos comportamentais podem estar contidos sob quatro designações: (a) condicionamento clássico; (b) análise do comportamento operante (isto é, modificação dos estímulos antecedentes e consequentes); (c) aprendizagem social; e (d) modificação cognitiva do comportamento / autocontrole" (p. 106).

2 O autor usa o termo valor como definido por Skinner (1972 apud Fawcett 1991), como afirmações do que é importante e que, se posto em prática, pode produzir reforçamento.

3 Segundo Velasco, Garcia-Mijares, Tomanari (2010): "Nesse tipo de delineamento, dois ou mais comportamentos são observados simultaneamente até que cada um atinja um estado-estável independente. Depois disso, a condição experimental é imposta sobre cada comportamento em diferentes momentos do experimento. Caso cada comportamento se altere somente depois de entrar em contato com a variável independente, supõe-se que tais mudanças decorreram das manipulações experimentais e não da operação de variáveis externas associadas à passagem do tempo. Esse tipo de delineamento é usado, principalmente, em estudos com humanos em situação terapêutica, em que, muitas vezes, há impedimentos éticos com relação à reversão do tratamento realizado" (p. 154). 